\title{
Prevention of weight gain during self-isolation in COVID-19 pandemic era: A narrative review
}

\author{
Harry Freitag Luglio Muhammad \\ Department of Nutrition and Health, Faculty of Medicine, Public Health and Nursing, Universitas Gadjah Mada, \\ Yogyakarta
}

ACCEPTED: 27 July 2020

KEYWORDS

COVID-19

Obesity

Nutrition

Physical activity

Self-isolation

\begin{abstract}
COVID-19 is a disease that has affected millions of people worldwide and made a significant impact on health, social life, and economy. One of the strategies to prevent the spread of this virus is through self-isolation. Although this strategy is efficient to prevent a drastic spread of the disease, there are some consequences related to this measure, including social, psychological, and economic impacts. In this review, the author proposes the possibility that this measure could increase the global prevalence of obesity. This might be due to a reduction in total physical activity because of limitations in outdoor activities, increased binge eating because of psychological stress or boredom, and tendency to eat ultra-processed foods and beverages because of limitations in shopping ability. Obesity itself is reported to be one of the risk factors for the severity of COVID-19 infection. Reports from United Kingdom and the United States of America revealed that those with higher body mass index had a higher risk to be treated at an intensive care unit. Therefore, prevention of a significant weight gain might be important to reduce the risk of fatality due to COVID-19. While the global prevalence of obesity is increasing worldwide, it might be important to address this issue at this point in time. Lastly, this review also provides some suggestions to ameliorate the weight gaining effect of self-isolation during the COVID-19 pandemic.
\end{abstract}

(c) The Journal 2020. This article is distributed under a Creative Commons Attribution-ShareAlike 4.0 International license.

\section{Introduction}

Individuals living with overweight and obesity are increasing worldwide. The World Health Organization (WHO) reported that the prevalence of obesity in 2016 tripled from the number of people in 1975. In 2016, it was estimated that 1.9 billion individuals in the world were either overweight or obese. This number represents $39 \%$ and $13 \%$ of individuals who are overweight and obese, respectively. ${ }^{1}$ In Indonesia, the prevalence of overweight and obesity is also increasing by $19.1 \%$ to $35.4 \%$ between 2007 and 2018. ${ }^{2}$ Obesity is associated with increased incidence of non-communicable diseases such as heart diseases, type 2 diabetes mellitus, cancer, and stroke. $^{3}$

Despite the great attention to the role of obesity

\footnotetext{
*Correspondence: harryfreitag@ugm.ac.id

Department of Nutrition and Health, Faculty of Medicine, Public Health, and Nursing, Universitas Gadjah Mada, Jl. Farmako, Sekip Utara, Yogyakarta 55281, Indonesia
}

in non-communicable diseases, it is recently reported that obesity was associated with greater severity of viral infection, especially Coronavirus Disease 2019 (COVID-19) infection. Originating from Wuhan, China, this virus has infected over 9 million individuals worldwide and claimed more than 500,000 lives (updated July 5,2020$).{ }^{4}$ In the initial reports, having old age was associated with an increased risk of disease severity. Interestingly, it is reported that individuals with higher body mass index (BMI) were more likely to have a severe response to COVID-19 infection. It is estimated that from most of the active cases, $98 \%$ were mild and only $2 \%$ are serious or critical. $^{4}$

On May $1^{\text {st }} 2020$, The Intensive Care National Audit and Research Center reported demographic data of COVID-19 confirmed patients admitted to critical ill wards across the United Kingdom. ${ }^{5}$ Of those 7542 patients, $73.3 \%$ were either overweight or obese with BMI higher than $25 \mathrm{~kg} / \mathrm{m}^{2}$. In addition 
to reports from the UK, other data from New York, United States of America have been recently reported, ${ }^{6}$ showing that among 3,615 individuals who were reported positive of COVID-19, 21\% and $16 \%$ were reported to be overweight and obese, respectively. Among patients with age less than 60 years old, being obese with BMI between 30-34 $\mathrm{kg} / \mathrm{m}^{2}$ was associated with 2 times higher risk of requiring acute care and 1.8 times more risk to be in critical care compared to those with BMI less than $30 \mathrm{~kg} / \mathrm{m}^{2}$. The risk significantly increases when a person's BMI is higher than $35 \mathrm{~kg} / \mathrm{m}^{2}{ }^{6}$

There are several proposed mechanisms linking obesity and severe response to COVID-19 infection, and one of them is increased inflammation. Obesity is associated with increases in both systemic and adipose tissue inflammation. This occurs through increased leptin production, infiltration of immune cells, reduction of proportion in anti-inflammatory mitochondria, and excessive production of proinflammatory cytokines. ${ }^{7}$ As a result, markers of systemic inflammation such as tumor necrosis factor (TNF)-alpha, Interleukin (IL)-6, and high sensitivity-C reactive protein (hs-CRP) are increased in individuals with obesity. ${ }^{7-9}$ The COVID-19 viral infection is thought to amplify the magnitude of inflammation state leading to a 'cytokine storm', which in turn will lead to the severity of this disease. ${ }^{10}$

Keeping normal adiposity is essential during the COVID-19 pandemic. However, the mechanisms underlying the interaction between obesity and COVID-19 is not the main focus of this review. As a response to this pandemic, the majority of governments all over the world recommend or strictly regulate their citizens' movements. Transportation across countries has been prohibited, while work and school learning are commonly done at home. This effort is aimed to reduce the transmission of the COVID-19 virus which in turn can prevent further outbreaks at the same time. However, the limitation of the movements of the citizens by social distancing and self-isolation has some consequences including the risk of weight gain. Several studies have indicated that self-quarantine related to the COVID-19 pandemic was associated with weight gain. ${ }^{11-13}$ This review aimed to propose selected factors that could contribute to weight gain during self-isolation. Because obesity has a negative impact on an individual's response to COVID-19 infection, suggestions were made to prevent such weight gain during the self-isolation period. The objective of this review is to propose a scenario in which self-isolation methods being used by major governments to prevent the spread of COVID-19 spread are causing widespread weight gain. In addition, the author also suggests several options to prevent the weight gain during this critical pandemic period of time.

\section{Method}

This review is divided into two sections. The first proposes mechanisms on how self-isolation could potentially induce weight gain. The second section of this review evaluates options to prevent weight gain during self-isolation. In this review, the author only provides a narrative review in which publications were not collected systematically. As reliable sources, reports from scientific publications were collected as well as organization reports from official websites.

\section{Result}

Despite the importance of self-isolation on the prevention of the spread of COVID-19 cases, this measure has had several consequences. The limited movement, increased free-time, psychological stress due to the inability to socialize physically or job loss, and limited options of food might lead to weight gain during self-isolation. To the author's knowledge, there are no reports regarding weight gain during this pandemic period of time.

\section{- Limited movements}

Being physically active is necessary to obtain ideal body weight and the prevention of cardiovascular diseases. A recent report showed that $27.5 \%$ of adults worldwide had insufficient physical activity. ${ }^{14}$ The trend of this prevalence was unchanged between 2001-2016. ${ }^{14}$ Different from global physical activity data, the prevalence of insufficient physical activity among adults in the South East Asia region was lower (14.7\%). ${ }^{15}$ Interestingly, the same report also showed that work-related physical activity has the highest proportion of physical activity 
compared to other components (transportation and recreational physical activity). In 2016, the author and colleagues conducted a cohort study in the city of Yogyakarta, Indonesia. ${ }^{16}$ This study involved as many as 503 adult men and women living in 5 districts in the city for at least 2 years. Subjects were followed from 2016. From this data, it was shown that the percentage of workrelated physical activity was $64 \%$ of the total activity, followed by household activities (20\%), transportation (10\%), and recreation (6\%) (data not shown).

The higher proportion of physical activity from work puts individuals at risk of becoming physically inactive during the self-isolation period. This is because currently there are many professions that are done at home, or so-called, work from home. Understanding the risks can help individuals know the dangers of weight gain and the importance of improving their lifestyle during isolation and thus preventing weight gain.

\section{- Psychological stress and boredom}

Psychological stress could also rise due to COVID-19 and several reasons might underlie this issue including lack of social interaction (physically), job losses due to lockdown, or health concerns. Stress itself is an important determining factor for binge eating disorder or BED. ${ }^{17}$ BED is a condition in which individuals have recurrent eating episodes usually involving eating a large amount of food at one time. In addition, BED is characterized as an eating episode accompanied by the feeling of inability to control the eating behavior. ${ }^{17}$ During prolonged stress, the hypothalamus-pituitary-adrenal (HPA) axis is hyperactive leading to cravings for caloric dense foods and beverages. In this condition, individuals have an increased preference for palatable foods to reduce the negative effect of stress, which is called the 'comfort food' hypothesis. ${ }^{18}$

In addition to stress, some people might find it challenging to adjust to doing all daily activity from home leading to reduced normal activity and plenty of spare time. This situation could lead to boredom, another physiological phenomenon that is rarely being studied. Different from stress, this condition could also increase the possibility of increased food-seeking behavior, leading to overconsumption. The connection between boredom and eating behavior has been studied recently. ${ }^{19,20}$ Moynihan et al. ${ }^{21}$ showed that the state of boredom was positively associated with caloric consumption. One of the explanations was through an increased desire for snack consumption.

\section{- Cooking at home and limited shopping options.}

Due to the so-called lockdown, some might experience a problem finding alternatives for healthier foods. In this period of time, not everyone can have easy access to fresh products such as vegetables and fruits. The majority of individuals, especially in the city, might have to rely on processed and instant foods such as noodles and canned meat/fish. It was also found that there is an increasing trend of consuming frozen products such as meatballs and nuggets. Those foods are relatively high in calories with less essential nutrients such as vitamins and minerals. Even though the food supply system was not affected by the outbreak, people are less likely to buy fresh products in bulk, and instead are buying foods which have high economic value and longer shelf life.

Consuming ultra-processed food has been reported to increase the risk of overweight and obesity. In Spain, The University of Navarra FollowUp (SUN) cohort study followed individuals for 8-9 years. This study revealed that those people with higher consumption of ultra-processed food had $26 \%$ relatively higher risk for becoming overweight and developing obesity in comparison to those with lower consumption of ultra-processed food ${ }^{22}$. There were several factors that might explain the influence of ultra-processed food consumption and obesity. First, ultra-processed food increases calorie intake, especially from sugars and fat. Second, consumption of these type of foods potentially reduces consumption of essential micronutrients such as vitamins and minerals. Third, ultra-processed foods have relatively lower fiber in comparison to 
Table 1. Example of ultra-processed foods and beverages

\begin{tabular}{lll}
\hline Beverages & Snacks others & Meal \\
\hline $\begin{array}{l}\text { Carbonated drinks } \\
\text { Energy drinks }\end{array}$ & $\begin{array}{l}\text { Sweet or savory packaged snacks } \\
\text { Ice-cream, chocolate, candies } \\
\text { (confectionery) }\end{array}$ & $\begin{array}{l}\text { Breakfast 'cereals', 'cereal' and 'energy' bars } \\
\text { Ready to heat products including pre-prepared pies and } \\
\text { pasta and pizza } \\
\text { Meat and chicken extracts and 'instant' sauces }\end{array}$ \\
$\begin{array}{l}\text { Milk drinks, 'fruit' Yoghurts } \\
\begin{array}{l}\text { Mnd 'fruit' drinks } \\
\text { Infant formulas, follow-on } \\
\text { milks, other baby products; } \\
\text { Cocoa drinks }\end{array}\end{array}$ & $\begin{array}{l}\text { Cookies (biscuits), pastries, cakes, } \\
\text { and cake mixes } \\
\text { Mass-produced packaged breads } \\
\text { and buns }\end{array}$ & $\begin{array}{l}\text { Health' and 'slimming' products such as powdered or } \\
\text { 'fortified' meal and dish substitutes } \\
\text { poultry and fish 'nuggets' and 'sticks', sausages, burgers, } \\
\text { hot dogs, and other reconstituted meat products, and } \\
\text { powdered and packaged 'instant' soups, noodles and } \\
\text { desserts. }\end{array}$ \\
\hline
\end{tabular}

their fresh counterparts ${ }^{22}$. The examples of ultraprocessed foods can be found in Table 1 based on NOVA $^{23}$.

\section{Discussion}

There are several strategies that can be used to prevent weight gain during the self-isolation of the COVID-19 pandemic. These strategies are proposed based on the three main reasons for weight gain during self-isolation.

\section{- Home exercise}

Home exercise has been previously reported to induce weight loss in a sustainable manner. Jakicic et al. ${ }^{24}$ showed that home exercise for 18 months was associated with a reduction of body weight among overweight women. Those who reduced more weight at the end of the program had the greatest exercise time duration (at least 200 minutes per week). This data revealed that having a regular exercise routine at home is beneficial for weight loss as well as prevention of weight gain.

The effect of home exercise is even better than group exercise at the fitness center for weight loss. Perri et al. ${ }^{25}$ compared the response to home-based exercise with groupbased exercise among women with obesity for 12 months. At the end of the intervention, this study showed that subjects with home-based exercise had higher participation in comparison to group-based exercise. In addition, subjects who regularly did home-based exercise had higher weight loss compared to group-based exercise.

To date, there are several exercise options available. Although home DVD exercise is no longer in fashion, there are abundant options for no-equipment home exercise at Internet platforms such as YouTube and Instagram. Also, several applications (apps) for personal trainers or exercise programs on mobile phones are widely available. The effectiveness of exercise apps on a mobile phone to increase leisure-time physical activity has been reported. ${ }^{26}$ Data on the effect of exercise apps on weight loss have been compiled and one meta-analysis showed that although the apps can influence weight reduction, the effect is rather small. ${ }^{27}$

\section{- Stress prevention and mood improvement foods}

Foods have long been reported to influence individuals' moods. There are several nutrients that have been reported to influence cognitive function and influence mood. Tryptophan is one of the essential amino acids found in food and has a role in the biogenesis of neuropeptide signals, namely serotonin. ${ }^{28}$ Serotonin is associated with improved moods since a lower serotonin level could reduce mood states. ${ }^{29}$ Tryptophan is rich in several nuts and seeds such as cashew, walnuts, almond, sesame, and soybeans. ${ }^{28}$ The beneficial effect of nut consumption on mood in a randomized controlled trial has been previously reported..$^{30}$ Accordingly, it is suggested that consuming nuts and seeds as a snack option 
might be beneficial to improve a person's mood during self-isolation.

Omega 3 has recently been suggested to also improve mood and prevent depression. ${ }^{31}$ This theory was initiated by several studies that reported that individuals with depression or anxiety had significantly lower omega 3 and higher omega $6 .{ }^{32,33}$ Several studies have reported that, despite the variation of results due to different characteristics of subjects, omega 3 supplementation could improve some of the clinical measures of stress or depression. ${ }^{31}$ One of the mechanisms linking this fatty acid is that omega 3 may maintain the HPA axis, which in turn could prevent disruption of a person's emotional state. The author recommends regular consumption of fish, especially fatty fish, which are high in omega 3 fatty acids.

\section{- Home prepared meals with fresh or frozen} vegetables

It is important to restrict the consumption of ultra-processed food whenever possible. Preparing fresh produce as a part of a healthy meal is necessary. However, when the condition is impossible to obtain fresh vegetables, selfpreparing frozen vegetables might be an option. Several vegetables and foods such as broccoli, cauliflower, corn, green peas, carrot, spinach, blueberries, and strawberries can be stored frozen. It was previously reported that the frozen storage of those foods still maintained similar micronutrients quantity than the fresh ones. ${ }^{34}$ Consumption of vegetables and fruits is important as one of the ways of prevention of obesity and its related diseases

\section{.5. Conclusion}

In summary, the author points out the importance of awareness that individuals might have increased risk of weight gain during self-isolation. This is because, until now it is unclear when the pandemic will stop and restrictions of human movement alleviated. Thus, it is important to keep a healthy lifestyle including practicing a home exercise program, avoiding binge eating, consuming foods that could improve our mental health, and avoiding ultra-processed foods and beverages whenever possible. Health promotion for our community in this time should focus not only on how to prevent disease spread, but also to improve everyone's well-being as well as prevent upcoming diseases after the pandemic is over.

\section{Acknowledgments}

The author thanks all healthcare workers who are in the first-line defense against this infection.

\section{Conflict of interests}

None declared.

\section{References}

1. Obesity and Overweight, updated 1 April 2020. https://www.who.int/news-room/fact-sheets/ detail/obesity-and-overweight (accessed at 3 May 2020).

2. Indonesian Ministry of Health. Basic Health Survey, Riskesdas 2018. Jakarta: 2019.

3. GBD 2015 Obesity Collaborators, et al. Health effects of overweight and obesity in 195 countries over 25 years. N Engl J Med. 2017; 377: 13-27.

4. COVID-19 CORONAVIRUS PANDEMIC. https:// www.worldometers.info/coronavirus/ (Accessed 3 May 2019).

5. Intensive Care National Audit and Research Center. https://www.icnarc.org/About/LatestNews/2020/04/10/Report-On-7542-PatientsCritically-III-With-Covid-19 (Accessed 3 May 2019)

6. Lighter J, Phillips $\mathrm{M}$, Hochman $\mathrm{S}$, et al. Obesity in patients younger than 60 years is a risk factor for COVID-19 hospital admission (published online ahead of print, 2020 Apr 9). Clin Infect Dis. 2020;ciaa415.

7. Han JM, Levings MK. Immune regulation in obesity-associated adipose inflammation. J Immunol. 2013;15:191(2):527-32.

8. Lumeng CN, Bodzin JL, Saltiel AR. Obesity induces a phenotypic switch in adipose tissue macrophage polarization. J Clin Invest. 2007; 117:175-184.

9. Tsoupras A, Lordan R, Zabetakis I. Inflammation, not cholesterol, is a cause of chronic disease. 
Nutrients. 2018;10(5):pii: E604.

10. Ryan PM, Caplice NM. Is adipose tissue a reservoir for viral spread, immune activation and cytokine amplification in COVID-19. Published online ahead of print, 2020 Apr 21. Obesity (Silver Spring). 2020;10.1002/oby.22843.

11. Zachary Z, Brianna F, Brianna L, et al. Selfquarantine and weight gain related risk factors during the COVID-19 pandemic. Obes Res Clin Pract. 2020;14(3):210-216.

12. Sidor A, Rzymski P. Dietary choices and habits during COVID-19 lockdown: experience from Poland. Nutrients. 2020;12(6):1657.

13. Pellegrini $M$, Ponzo V, Rosato $R$, et al. Changes in weight and nutritional habits in adults with obesity during the "Lockdown" period caused by the COVID-19 virus emergency. Nutrients. 2020;12(7):E2016.

14. Guthold R, Stevens GA, Riley LM, Bull FC. Worldwide trends in insufficient physical activity from 2001 to 2016: a pooled analysis of 358 population-based surveys with 1.9 million participants. published correction appears in Lancet Glob Health. 2019 Jan;7(1):e36. Lancet Glob Health. 2018;6(10):e1077-e1086.

15. World Health Organization. Regional Office for South-East Asia. (2018). Status report on 'physical activity and health in the South-East Asia Region': July 2018. World Health Organization. Regional Office for South-East Asia. https://apps.who.int/ iris/handle/10665/274308.

16. Muhammad HFL, van Baak MA, Mariman EC, et al. Dietary inflammatory index score and its association with body weight, blood pressure, lipid profile, and leptin in Indonesian adults. Nutrients. 2019;11(1):148.

17. Razzoli M, Pearson C, Crow S, Bartolomucci A. Stress, overeating, and obesity: insights from human studies and preclinical models. Neurosci Biobehav Rev. 2017;76(Pt A):154-162.

18. Dallman MF. Stress-induced obesity and the emotional nervous system. Trends Endocrinol Metab. 2010;21(3):159-165.

19. Crockett AC, Myhre SK, Rokke PD. Boredom proneness and emotion regulation predict emotional eating. I Health Psychol. 2015;20(5):670-680.
20. Koball AM, Meers MR, Storfer-Isser A, Domoff $\mathrm{SE}$, Musher-Eizenman DR. Eating when bored: revision of the emotional eating scale with a focus on boredom. Health Psychol. 2012;31(4):521-524.

21. Moynihan $A B$, van Tilburg WA, Igou ER, Wisman $A$, Donnelly $A E$, Mulcaire JB. Eaten up by boredom: consuming food to escape awareness of the bored self. Front Psychol. 2015;6:369.

22. Mendonça RD, Pimenta AM, Gea A, et al. Ultraprocessed food consumption and risk of overweight and obesity: The University of Navarra Follow-Up (SUN) cohort study. Am J Clin Nutr. 2016;104(5):1433-1440.

23. Monteiro CA, Cannon G, Levy R, Moubarac JC, Jaime $P$, Martins AP, Canella D, Louzada M, Parra $D$, Ricardo C, et al. Food classification. Public health. J World Public Health Nutr 2016;7:28-38.

24. Jakicic JM, Winters C, Lang W, Wing RR. Effects of intermittent exercise and use of home exercise equipment on adherence, weight loss, and fitness in overweight women: a randomized trial. JAMA. 1999;282(16):1554-1560.

25. Perri MG, Martin AD, Leermakers EA, Sears SF, Notelovitz $M$. Effects of group- versus homebased exercise in the treatment of obesity. $J$ Consult Clin Psychol. 1997;65(2):278-285.

26. Litman L, Rosen Z, Spierer D, Weinberger-Litman $S$, Goldschein A, Robinson J. Mobile exercise apps and increased leisure time exercise activity: a moderated mediation analysis of the role of self-Efficacy and barriers. I Med Internet Res. 2015;17(8):e195

27. Flores Mateo G, Granado-Font E, Ferré-Grau C, Montaña-Carreras X. Mobile phone apps to promote weight loss and increase physical activity: a systematic review and meta-analysis. $J$ Med Internet Res. 2015;17(11):e253.

28. Strasser B, Gostner JM, Fuchs D. Mood, food, and cognition: role of tryptophan and serotonin. Curr Opin Clin Nutr Metab Care. 2016;19(1):55-61.

29. Jenkins TA, Nguyen JC, Polglaze KE, Bertrand PP. Influence of tryptophan and serotonin on mood and cognition with a possible role of the gutbrain axis. Nutrients. 2016;8(1):56.

30. Pribis P. Effects of walnut consumption on mood in young adults: a randomized controlled trial. 
Nutrients. 2016;8(11):668.

31. Larrieu T, Layé S. Food for mood: relevance of nutritional omega-3 fatty acids for depression and anxiety. Front Physiol. 2018;9:1047.

32. Green $P$, Hermesh $H$, Monselise A, Marom $S$, Presburger $G$, and Weizman $A$. Red cell membrane omega-3 fatty acids are decreased in nondepressed patients with social anxiety disorder. Eur. Neuropsychopharmacol. 2006;16:107-113.
33. McNamara RK, Hahn CG, Jandacek R, Rider T, Tso $P$, Stanford KE, et al. Selective deficits in the omega-3 fatty acid docosahexaenoic acid in the postmortem orbitofrontal cortex of patients with major depressive disorder. Biol. Psychiatry. 2007;62:17-24.

34. Lia L, Pegga RB, Eitenmillera RR, Chunb JY, Kerrihard AL. Selected nutrient analyses of fresh, fresh-stored, and frozen fruits and vegetables. $J$ Food Compost Anal. 2017;59:8-17. 